1 Anonymous. Top docs blast lazy GPs who coin it in. Sun 1984 Oct 31:5 2 Jones B. Hours report is a bitter pill for GPs. Mail on Sunday 1984 Nov $11: 8-9$

3 Thomas J. Report exposes 20-hour week. Doctor 1984 Nov 1:1.

4 Relman AS. The Ingelfinger rule. $N$ Engl F Med 1981;305:824-6.

5 McBride G. Now for the latest news. JAMA 1981;245:374-5.

6 Grouse L.D. The Ingelfinger rule. 7AMA 1981;245:375-6. Anonymous. Medical journals and urgent medical news [Editorial]. Ann Intern Med 1983;99

\section{What can we do about measles?}

A recent article described an outbreak of five cases of measles.' This episode occurred in the United States, and the fact that it was thought sufficiently important to warrant publication underlines the remarkable progress made there in controlling measles, certainly when compared with our own poor performance. (Ironically, the source of the outbreak was traced to a 17 year old English citizen who was visiting that country.)

In 1983 active surveillance uncovered only 1436 cases of measles in the United States, a rate of $0 \cdot 6 / 100000$ total population. ${ }^{2}$ The index case in the outbreak had travelled with a drum and bugle corps over 10000 miles through 24 states, but created a chain of no more than four known cases of measles. This testifies not only to the solid immunity induced in the population by mass vaccination but also to the energetic measures to control the outbreak. One thousand contacts or potential contacts were vaccinated and a further 500 were able to avoid vaccination only by showing proof of immunity to measles. The emergency immunisation clinics were held until after midnight "to maximise participation and minimise interference with the [drum and bugle] competitions."

The United States set 1 October 1982 as a target date for eliminating measles, and the fact that this has not been quite achieved says more for the target being unrealistic than for any failure in effort. At present eradication is a goal based more on politics and idealism than on the pragmatism of cost effectiveness. ${ }^{3}$ Moreover, if, as Rabo and Taranger believe,${ }^{4}$ there is a danger that the incidence of measles will eventually rise in adults in countries in which there is a policy of mass measles immunisation in childhood, eradication should not be attempted except on a worldwide basis. The outbreak in question was contained to four secondary cases, but at a cost of much effort, and, given the high level of immunity already achieved throughout the country, the number of cases or chains of cases prevented by this effort is unlikely to have been very many.

Until worldwide eradication or elimination of measles is feasible, perhaps we do not need to set our sights so high. That is not to say, however, that in Britain we do not have considerable scope for improvement. In 1983 England and Wales achieved its highest average national uptake for measles vaccine for children reaching their second birthday -of $59 \%{ }^{5}$ This is a derisory figure compared with the $97 \%$ coverage the United States has achieved since 1982. Canada has set a similar target to that of the United States, and three countries in Europe-Czechoslovakia, Sweden, and Finland-have set goals of elimination of indigenous measles. ${ }^{6}$ Czechoslovakia is already well on the way to achieving her target, with only 25 recorded cases in 1982, most of them imported. Sweden and Finland have started more recently but will undoubtedly do well.

A recent health notice from the DHSS has laid down a target of $90 \%$ vaccine coverage by 1990 , at which level "efforts to eliminate measles could be made." Though this may seem modest by the standards of other countries, it is probably realistic_especially if, as the Swedes have found, two doses of measles vaccine are required to eliminate the disease ${ }^{4}$ Levels of measles vaccine uptake by district in 1983 ranged from $28 \%$ to $85 \%$, and the higher figure shows what can be done, presumably by enthusiasm and efficiency, within the existing framework of the health services in this country. Though enthusiasm and motivation undoubtedly exist, ${ }^{7}$ district health authorities are now being asked specifically to offer measles immunisation to all susceptible children entering preschool playgroups, nursery schools, and primary schools; and, after reviewing the immunisation state of children at the school medical examination, to offer immunisation when necessary.

Unfortunately, the criteria for susceptibility are not clearly set out in the DHSS document. In the United States immunity means written documentation showing the date of vaccination with live measles vaccine on or after the first birthday, or a history of measles diagnosed by a physician. The criteria for immunisation after the review of immunisation state at the school medical examinations are also not specified. Nevertheless, the campaign scheduled to start in the autumn, and forecast by The Times in April, ${ }^{8}$ will perhaps herald a new and vigorous attitude on the part of our health services to this, one of the most demonstrably cost effective of vaccines.

N D NOAH

Consultant Epidemiologist,

Public Health Laboratory Service Communicable

Disease Surveillance Centre.

London NW9 5EQ

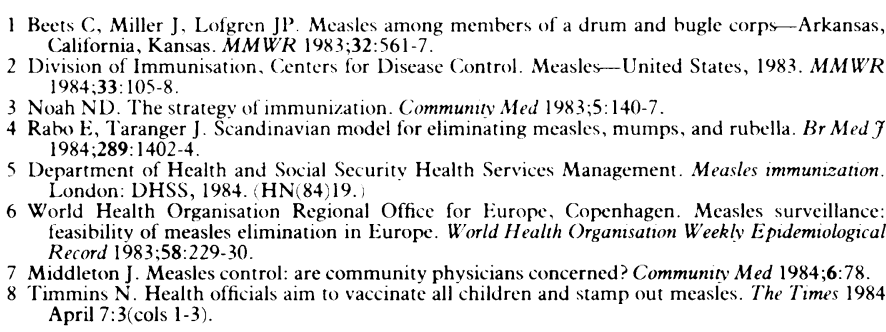

\section{Skin disease: the link with zinc}

Zinc joined the miners in the news a few weeks ago after a report that it had helped a girl with anorexia nervosa. ${ }^{1}$ The public fancy was tickled-as it had not been by earlier reports of zinc deficiency in anorectics ${ }^{2}$-and the blazing headlines confirmed that zinc has long since ended its slow struggle up the evolutionary ladder to a secure place in human medicine.

Black bread mould has been known to need zinc since 1869; plants since 1926; rats since 1934; pigs since 1955; and cattle since $1960 .^{3}$ At that stage several zinc deficiency diseases had been recognised in animals, differing in detail but tending to share as their main features retarded growth, hypogonadism, alopecia, and skin lesions. The time was ripe for the discovery of a similar zinc deficiency state in man.

The gap was filled in 1961 by a group of anaemic clay eating Iranian dwarís with absent secondary sex charac- 